\title{
Promoting Hotel Managerial and Operational Level with new Technology
}

\author{
Li yunpeng ${ }^{1, a}$, Xie yongqiu ${ }^{2, b}$,Huang Chao ${ }^{3, c}$
}

${ }^{1}$ School of Government, Peking University, Beijing, China; Department of Tourism Management, Capital University of Economics and Business, Beijing, China

${ }^{2}$ Department of Tourism Management, Capital University of Economics and Business Beijing, China

${ }^{3}$ Department of Tourism Management, Capital University of Economics and Business Beijing, China

a liyunpeng2008@gmail.com, bieyongqiu321@163.com, c huangchao19860403@126.com

\section{Keywords: New Technology; Hotel Management; Promoting Performance}

\begin{abstract}
IT, typically represented by computer technology, has laid a solid foundation for the hotel Informatization. At present, most of guest serving and receiving business are processed with IT. But still, there is some inadequacy in the controlling system of distribution channels. To solve these problems and to meet needs, more and more newly invented technologies are applied in IT-based hotel management. Like internet of Things technology, distribution technology, cloud computing. Presently, in China's market numbers of entrepreneurs are committed to try to take advantage of these new technologies in hotel operation and management. But the most important things are to fully consider the applicability of the information technology and to realize of unified and unimpeded information flow. Following are the steps to be adopted: Information standardization and reservation procedure standardization, Hotel networking, Hotel service creation, Application of socialized media, Prompt service and customized service.
\end{abstract}

\section{Introduction}

Before elaboration what needs to be explained is that although a new technology can generate improvement of work efficiency, its application should not be regarded as an ultimate target. Indeed, a new technology can greatly improve the efficiency of an operational procedure and optimize hotel management, but, to some extent, the improvements depend well on how the procedure is understood by the managers and executers and how it is implemented.

In information times the worldwide application of IT, typically represented by computer technology, has laid a solid foundation for making extensive use of information. As an impressive feature of our age, information has become a great resource. Generally, hotel information involves many aspects, such as organizational structure, product, market, financial status, human resources, asset portfolio, fixed assets, process of production and service, management situation, sales analysis, client distribution and internal environment, etc. As a result, the improvement of management efficiency, generated by information technology, will produce operational yield.

\section{Present Situation and Main Problem in Hotel Management Systems}

There is a large variety of the technological application involving hotel management. From the perspective of a hotel's IT-based management and operation, the application falls into two categories: service distribution technology and internal managerial and operational technology. Namely, most of guest serving or receiving business is processed with IT. But still, there is some inadequacy in the controlling system of distribution channels.

On-line room reservation market is characterized by diversified business channels and reservation approaches. In the reservation process different types of people are engaged in business, involving miscellaneous organizations. Meanwhile, the reservation channel of a hotel needs to be supported by database system, which demands accurate information from uniformly equipped data supply channels. Once a hotel's product data and reservation procedure is standardized, the reservation market will become well developed. But what it really is that no integrated reservation 
management system is constructed in most hotels and reservation data has not been placed under uniformed management and optimized usage. Specifically, the common problems in this regard are as follows: separately developed distribution systems, non-uniformed technical standards, inconsistent reservation procedure and unsmooth flow of information and data. Consequently, management information, business intelligence and decision-making strategies cannot be shared among different functional divisions for free and mutual application. Moreover, the hotel management has to confirm the reservation information for each of the individual distribution channels and replace the website information from time to time. Just due to the tremendous work of order typing and booking correction and cancellation, data accuracy and promptness cannot be guaranteed and the hotel's IT- based operational system is severely constrained by all these drawbacks. So achieving a smoothly moving information flow is regarded as an important task for constructing IT-based management system. Nowadays, developing Internet on-line reservation system has become a trend. It is essential to connect the distribution system with other network service platforms. And all the on-line distribution systems need be mutually connected on uniformed technology standards.

\section{Solutions for Hotel Management Systems}

With regard to hotel business operation, the available computer software can only help the managers optimize internal managerial procedure. But sill, there is some inadequacy, such as how to improve the overall operational level and how to steadily increase earnings. As a result, a hotel (or a corporate group) is in need of a distribution technique or a solution to improve transaction-processing capability for itself and distributers. Such capability is meaningful for both parties to lower operational cost and reduce transaction-awaiting time. And this helps the hotel reach the goal of yield management. Presently, in China's market numbers of entrepreneurs are committed to solve these problems, for instance, China-Online, (Chang Joint Logistics) Debi, Huitongtianxia (Land of Wealth) in Shanghai and Luopan, Zhongruan in Beijing. With the development of new technology, more and more newly invented technologies are applied in IT-based hotel management.

\section{(1) Application of Internet of Things technology in intelligent hotels.}

IBM is regarded as one of the representative organizations in which intelligent RFID card is used in business, such as real-time customer service, customer information identification, service guidance, route planning and customer expense recording.

(2) Application of distribution technology.

The representative companies are HuiItongtianxia,(HUBS1), Deby and China-Online. HUBS1 has installed a central reservation system for establishing an advanced platform between upper stream hotels and lower stream tourism distributers to handle on-line reservation, tour group distribution, routine management and account settlement. The adoption of such technology makes the hotel's IT system compatible with those of distribution channels so that the information on room rates or occupancy becomes more transparent.

DEBI software applies computer interfacing technology to constructing and running new generation global tourism distribution system to build business contact between tourism product suppliers and their distributers. In this way the company has created a global tourism distribution system which offers managerial function and other value-added service.

China-Online applies SWITH technology and realizes the double-way seamless connection between hotels and their distributers. The actual effect is as follows: regulating the data standardization of each individual hotel's reservation system so as to increase the promptness of information transmission between different hotels; reducing information transmission routes between the hotel and its reservation system; reducing labor cost to maintain the data respectively for the hotel front desk, the back office's information system and its reservation system. The reservation efficiency has been increased, operational cost reduced and operational yields increased.

\section{(3) Application of cloud computing.}

The representative enterprise is LUOPAN. Cloud computing is a model of outsourcing new types 
of IT business, which exploits the third party's platforms for marketing and day to day administration and saves costs of system management, maintenance and marketing affairs. IT service outsourcing has become a new trend, which is a service-oriented operational model and offers external technical support for information management in the hotel.

\section{Innovations in Hotel Management}

When applying IT to solve operational and managerial problems, the hotel needs to take an overall view. All needs and facts must be put into consideration. Only in this way could the hotel's managerial efficiency and operational yield be promoted. Following are the steps to be adopted:

\section{(1) Information standardization and reservation procedure standardization}

More new technologies need to be adopted for promoting the growth of hotel industry. To technicalize hotel industry, effective operational standards should be enforced. Through standardizing hotel business scope, tourism administration can implement uniformed standards of business procedure and information prescription. As a result, individual hotel's operation will be improved, and further, the growth of tourism industry upgraded. However, only one standard has been implemented in regard to IT-based management in the hotel, the title of which is SB/T 10522-2009, IT-based Hotel Facility Standard. Instead of stressing operation and management, this standard just placed emphasis on IT-based facilities and the concerning technologies. If the technological solution can generate a full set of standards of information description and data interchange, the IT- based business contacts will be well directed and regulated in the whole tourism industry. And the overall managerial and operational level promoted as well.

In terms of the hotel's needs for information usage, data processing procedure, interfacing and data attribute need to be standardized. This ensures that data can be seamlessly integrated and its accuracy and work efficiency improved as well.

The standardization of information and data, uniformed distribution systems and hotel internal management data are meaningful for carrying out data standardization. For example, by applying the directly connecting technology of China-Online, a hotel can directly connect its information system to those of distribution channels. The standardization of interfacing connecters helps each work unit save the workforce to maintain the equipments. Correspondingly, the hotel's data accuracy and room reservation confirming rate is increased as a result.

\section{(2) Hotel networking}

Network has strong impact on hotel operation, which changes the competition norms of hotel industry as well as the ways of service. Meanwhile, hotel networking, operating, marketing, room booking and information using, etc all have been changed. The typical examples are Star Alliance and China Hotel Alliance. They are virtual hotel alliances in the age of networking.

Operation networking: The hotel connects its internal IT-based management system with external Internet so that it can develop effective contact with customers and offer them tailored service.

Reservation network: The application of global distribution system and central reservation system gives the hotel more accessibility to a great number of large markets in remote areas.

Information networking: The development of network technology generated the networking of office information and customer information and promoted information circulation with electronic apparatus and equipments. But the external on-line reservation system has been seamlessly connected with the information systems of front desk and financial division in the hotel. Such a connection helps executives learn about the hotel's operation status as promptly as possible. The application of Mobile Office and Video conference technology has increased managerial and operational efficiency.

\section{(3) Hotel service creation}

The hotel can divide customer service into several parts and develop each of them on different networking platforms, for instance, network printing, holiday entertainment service, etc. With more IT-based service platforms, the hotel can offer more fine service to its customers and improve the quality of their personal experience. 


\section{(4) Application of socialized marketing media}

By enhancing the customers' needs of interaction with the hotel, e g, opening micro-blog, happy net or other socialized media platforms, the hotel can take more interactions with customers and improve its public profile.

\section{(5) Prompt service and customized service}

Modernized intelligent hotels can be constructed if the service demand is transmitted through network platforms. IBM's experience is a typical example. When the construction of smart hotel completed, customers' intelligent level (their ability to match smart equipments and facilities) has been upgraded. Meanwhile, employee's work efficiency is promoted and the hotel's operational cost is put under control as well.

In conclusion, through applying IT-based systems, a hotel (or a corporate group) improves its management as a whole. Specifically, the improvements are in the following aspects:

----The managerial level and technological applying capability of the hotel industry;

----The overall operational capability, competition competence of an individual hotel or a hotel corporate group, the potential to lower cost;

---- An individual hotel can gradually standardize the data, interface of its information system to improve marketing and internal management. With the standardization, technology access to IT-based management will become relatively lower and IT-based management level of the whole hotel industry will be promoted to a higher degree.

\section{References}

[1] Yuan Xueya, Guests' Needs for new-high tech of house-keeping management in the future hotel, China Tourism News, 2000-10-11 (B02).

[2] Wang Dongwei, Solution to new intelligent technology in modern star hotel, J. Journal of Intelligent Building, 2009, (8).

[3] Duanjun, New communications technology in modern hotel, J. Journal of Post and Telecommunications Business, 1997,(21).

[4] Wang Dawu, New technology of energy management in contemporary hotel. China Tourism News, 2002-12-04

[5] Yuxin, Switch technology changes the distribution pattern of hotel industry, 2009-04-13. http://www.xcf.cn/newfortune/qianyan/200904/t20090413_240473.htm[EB/OL] 